\title{
Linking estrogen receptor $\beta$ expression with inflammatory bowel disease activity
}

\author{
Marina Pierdominici ${ }^{1}$, Angela Maselli², Barbara Varano ${ }^{3}$, Cristiana Barbati ${ }^{1}$, Paola \\ Cesaro ${ }^{4}$, Cristiano Spada ${ }^{4}$, Angelo Zullo5, Roberto Lorenzetti ${ }^{5}$, Marco Rosati ${ }^{6}$, \\ Gabriella Rainaldi ${ }^{3}$, Maria Rosaria Limiti ${ }^{6}$, Luisa Guidi', Lucia Conti ${ }^{3, *}$ and Sandra \\ Gessani ${ }^{3, *}$ \\ ${ }^{1}$ Department of Cell Biology and Neurosciences, Istituto Superiore di Sanità, Rome, Italy \\ 2 Department of Therapeutic Research and Medicines Evaluation, Istituto Superiore di Sanità, Rome, Italy \\ ${ }^{3}$ Department of Hematology, Oncology and Molecular Medicine, Istituto Superiore di Sanità, Rome, Italy \\ ${ }^{4}$ Digestive Endoscopy Unit, Catholic University, Rome, Italy \\ ${ }^{5}$ Gastroenterology and Digestive Endoscopy, Nuovo Regina Margherita Hospital, Rome, Italy \\ ${ }^{6}$ Histopathology Complex Unit, Santo Spirito Hospital, Rome, Italy \\ 7 IBD Unit, Complesso Integrato Columbus, Catholic University, Rome, Italy \\ * These authors jointly supervised this work \\ Correspondence to: Lucia Conti, email: Iucia.conti@iss.it
}

Sandra Gessani, email: sandra.gessani@iss.it

Keywords: estrogen receptors, inflammatory bowel disease, T lymphocytes, inflammation, cytokines, Immunology and Microbiology Section, Immune response, Immunity

Received: September 08, $2015 \quad$ Accepted: October 02, $2015 \quad$ Published: October 22, 2015

This is an open-access article distributed under the terms of the Creative Commons Attribution License, which permits unrestricted use, distribution, and reproduction in any medium, provided the original author and source are credited.

\section{ABSTRACT}

Crohn disease (CD) and ulcerative colitis (UC) are chronic forms of inflammatory bowel disease (IBD) whose pathogenesis is only poorly understood. Estrogens have a complex role in inflammation and growing evidence suggests that these hormones may impact IBD pathogenesis. Here, we demonstrated a significant reduction $(p<$ 0.05 ) of estrogen receptor (ER) $\beta$ expression in peripheral blood T lymphocytes from $\mathrm{CD} / \mathrm{UC}$ patients with active disease $(n=27)$ as compared to those in remission ( $n$ $=21$ ) and healthy controls $(n=29)$. Accordingly, in a subgroup of CD/UC patients undergoing to anti-TNF-a therapy and responsive to treatment, ER $\beta$ expression was higher $(p<0.01)$ than that observed in not responsive patients and comparable to that of control subjects. Notably, ER $\beta$ expression was markedly decreased in colonic mucosa of CD/UC patients with active disease, reflecting the alterations observed in peripheral blood T cells. ER $\beta$ expression inversely correlated with interleukin (IL)-6 serum levels and exogenous exposure of both $\mathrm{T}$ lymphocytes and intestinal epithelial cells to this cytokine resulted in ERß downregulation. These results demonstrate that the ER profile is altered in active IBD patients at both mucosal and systemic levels, at least in part due to IL-6 dysregulation, and highlight the potential exploitation of $T$ cell-associated ER $\beta$ as a biomarker of endoscopic disease activity.

\section{INTRODUCTION}

Crohn disease (CD) and ulcerative colitis (UC) are chronic forms of inflammatory bowel disease (IBD) arising from the combined effects of genetic susceptibility, environmental influences, intestinal dysbiosis, and innate and adaptive immune system dysregulation, leading to chronic inflammation and subsequent tissue damage [1, 2 ]. TNF- $\alpha$, a molecule with a broad spectrum of activity, including costimulation of lymphocyte inflammatory functions and direct disruption of intestinal epithelial barrier integrity, has a well-established pathological role 
Table 1: Demographic and clinical characteristics of the study sample

\begin{tabular}{|c|c|c|}
\hline & CD & $\mathbf{U C}$ \\
\hline Patients, $n$ of patients & $26 / 48$ & $22 / 48$ \\
\hline Age (years), median (range) & $45(19-70)$ & $44(19-68)$ \\
\hline Women/men & $11 / 15$ & $10 / 12$ \\
\hline Endoscopic remission ${ }^{\mathrm{a}}, \mathrm{n}$ of patients $(\%)$ & $12(46)$ & $9(41)$ \\
\hline \multicolumn{3}{|l|}{ Current drug therapy, $\mathrm{n}$ of patients $(\%)$} \\
\hline 5-aminosalicylic acid & $8(31)$ & $10(45)$ \\
\hline Systemic corticosteroid & $2(7)$ & $2(9)$ \\
\hline Anti-TNF $\alpha$ (Infliximab/Adalimumab) & $12(46)$ & $7(32)$ \\
\hline
\end{tabular}

aCD: Crohn's Disease Endoscopic Index of Severity (CDEIS, remission when score < 3); post-operative CD: Rutgeerts score (remission when score $=\mathrm{i} 0$ ); UC: Mayo endoscopic sub-score (remission when score $=0$ ).

in IBD and has been successfully exploited as a target for therapeutic intervention [3]. However, subgroups of IBD patients fail to respond or lose response to this drug indicating that the immune networks in the inflamed mucosa are complex and subjected to multiple layers of regulation by still unrecognized factors [3].

Growing evidence from epidemiological and experimental studies suggests a role for estrogens, particularly $17 \beta$ estradiol, in IBD pathogenesis [4-14]. Estrogens have been shown to finely regulate inflammation [15] and have been implicated in the modulation of several immune-mediated diseases $[16,17]$. Most of their effects are mediated by two intracellular receptors, i.e, estrogen receptor (ER) $\alpha$ and ER $\beta$, which function as ligandactivated nuclear transcription factors producing genomic effects [15]. ERs are expressed in different cell types including immune cells [18-21] and the presence of one ER subtype over the other may change estrogen effects, promoting or dampening inflammation [15].

$\mathrm{ER} \beta$ is the predominant ER subtype in colon tissue, where it plays a fundamental role in growth, organization and maintenance of normal epithelial architecture $[12,22$, 23]. Interestingly, reduced ER $\beta$ mRNA expression and increased gut permeability were found to precede the onset of colitis in mouse models of intestinal inflammation [12]. Additionally, ER $\beta$ knockout mice developed a clinically more severe colitis as compared to wild-type littermates [13]. In keeping with these findings, beneficial effects of ER $\beta$ agonists as well as estrogens have been reported in different models of chronic colitis [9-11, 14]. There is also evidence that estrogens can modulate disease severity in IBD patients [4-6]. However, ER expression in human IBD and its possible correlation with disease activity have been till now poorly investigated, with the exception of one study by Looijer-van Langen et al. [12] showing decreased ER $\beta$ mRNA levels in colonic biopsies from $\mathrm{CD}$ patients in relapse, but not in remission. Notably, UC and $\mathrm{CD}$ are associated with an increased risk of colorectal cancer (CRC) that appears to increase with the duration, severity and anatomic extent of colonic inflammation $[24,25]$. In this respect, growing data support a role for
estrogen/ER in the initiation and progression of CRC, and establish that protective effects of estrogen are exerted through ER $\beta$ [26-28].

In this study we report IBD-associated alterations of ER expression profile both in peripheral blood $\mathrm{T}$ lymphocytes and in colonic mucosa and their relationship with the clinical characteristics of the studied population. We also identified interleukin (IL)-6 as an unrecognized regulator of ER expression in circulating $\mathrm{T}$ cells and intestinal epithelium.

\section{RESULTS AND DISCUSSION}

\section{ERß expression is downregulated in peripheral blood $\mathrm{T}$ lymphocytes from active IBD patients}

We evaluated by flow cytometry the intracellular expression of $E R \alpha$ and $E R \beta$ in peripheral blood $T$ lymphocytes from 48 patients with IBD (CD, $n=26$ and $\mathrm{UC}, n=22$ ) and 29 age/sex matched healthy controls (HC). The demographic and clinical characteristics of IBD patients are summarized in Table 1. A significant increase of $\operatorname{ER} \alpha$ and a concomitant decrease of ER $\beta$ expression were observed in $\mathrm{T}$ lymphocytes from IBD patients as compared to $\mathrm{HC}$, whereas no differences were detected between $\mathrm{CD}$ and $\mathrm{UC}$ patients (Figure $1 \mathrm{~A}$ and $1 \mathrm{~B}$ ). Similar results were obtained when purified $\mathrm{CD}^{+}$and $\mathrm{CD}^{+} \mathrm{T}$ cells were analyzed separately (data not shown). For both $\mathrm{ER} \alpha$ and ER $\beta$ expression, no significant associations were found with the epidemiological data (sex, age) of the patient population. To estimate whether ER expression level reflects disease activity, the patient population was divided into 2 groups according to the endoscopic activity at the time of sampling, i.e., patients with active disease and those in remission (see Materials and Methods and Table 1 for details). Although ER $\alpha$ expression was not significantly different in $\mathrm{T}$ cells from patients in remission and those with active disease (Figure 1C), a significantly lower expression of ER $\beta$ was found in T cells from $\mathrm{CD}$ / 
UC patients with active disease as compared to those in remission (Figure 1D).

Although ERs have been shown to finely regulate inflammation [15], this is the first demonstration of a specific alteration of ER profile in IBD. The current diagnosis and management of IBD is based on clinical and endoscopic criteria [29]. More specifically, as routine clinical assessment is often inaccurate with respect to endoscopic activity [30], colonoscopy represents the gold standard technique for the evaluation of disease severity. However, due to the complexity and invasiveness of this practice, there is a pressing need for new non-invasive biomarkers to improve disease activity detection, in order to better determine prognosis and to monitor drug response. In this regard, the strong association between lymphocyte ER $\beta$ levels and endoscopic disease activity observed in our study points to this receptor as a potential prognostic biomarker for IBD.

Interestingly, blood $\mathrm{T}$ lymphocytes from a subgroup of $\mathrm{CD} / \mathrm{UC}$ patients in ongoing treatment with anti-TNF- $\alpha$ (infliximab or adalimumab: 12/26 CD and $7 / 22$ UC) showed significantly different expression of ER $\beta$ according to drug response, as monitored by the endoscopic activity. Specifically, responsive patients $(n=8)$ expressed higher levels of ER $\beta$ as compared to unresponsive patients $(n=11)$ (Figure 1E). The expression of $\mathrm{ER} \alpha$ was found to be not significantly different between these 2 groups of patients (Figure 1F). As response to therapy has been established on the basis of disease remission at the endoscopic level, our findings
A

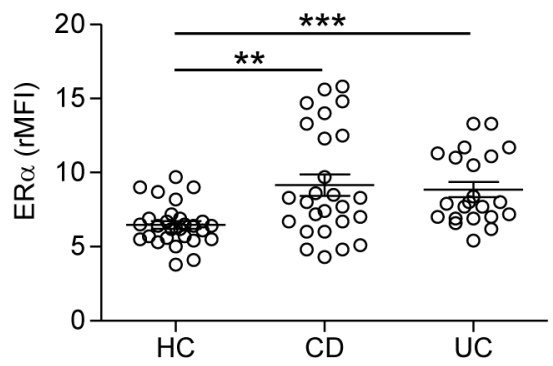

C

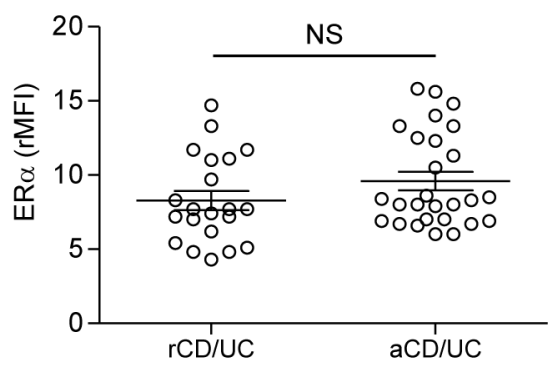

E

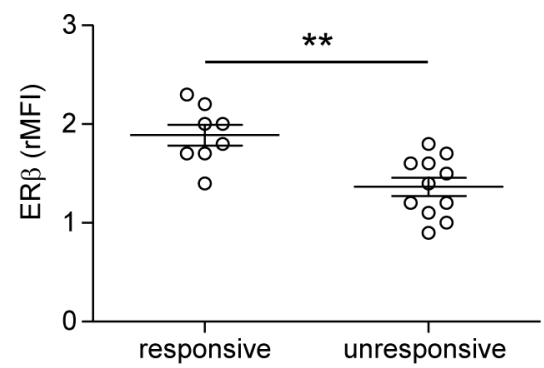

B

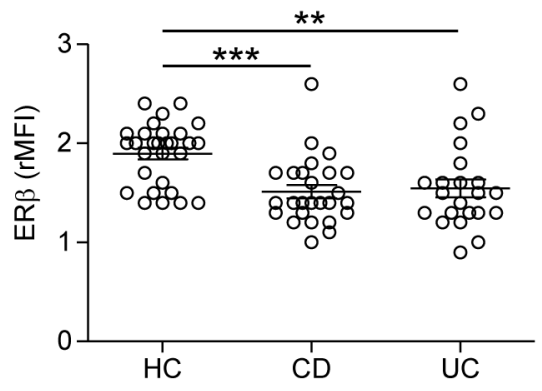

D

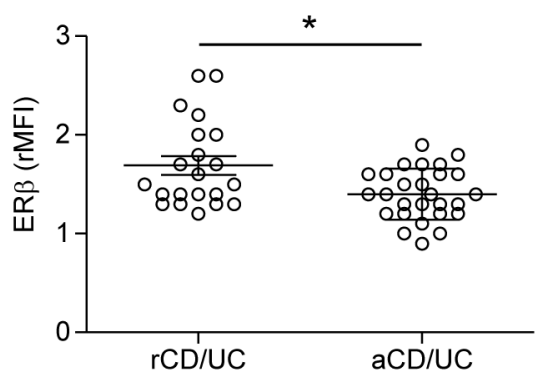

F

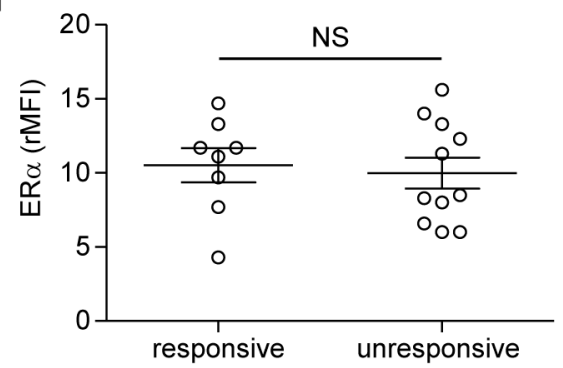

Figure 1: Intracellular ER expression in peripheral blood T lymphocytes from CD/UC patients. A.-D. Intracellular ER $\alpha$ and ER $\beta$ expression levels evaluated by flow cytometry in T cells from CD/UC patients, considered as a whole $(n=48)$ or divided in patients in remission $(n=21)$ and those with active disease $(n=27)$ according to the endoscopic activity, and from healthy controls (HC; $n=29)$. E., F. Intracellular ER expression evaluated in T cells from a subgroup of CD/UC patients in ongoing treatment with anti-TNF- $\alpha$ $(n=19)$, divided in responsive $(n=8)$ and unresponsive $(n=11)$ patients. Values of ER/isotype control mean fluorescence intensity ratio (rMFI) are reported (mean \pm SEM is shown for each group). Statistical differences were calculated by the Mann-Whitney $\mathrm{U}$ test. ${ }^{*} p<$ $0.05 ; * * p<0.01 ; * * * p<0.001$. NS, nonsignificant; $\mathrm{rCD} / \mathrm{UC}, \mathrm{CD} / \mathrm{UC}$ patients in endoscopic remission; aCD/UC, CD/UC patients with endoscopic activity. 
further strengthen the role of $\mathrm{T}$ cell-associated $\operatorname{ER} \beta$ as a systemic marker of intestinal disease activity. Additionally, the association found between anti-TNF- $\alpha$ response and normal ER $\beta$ levels in blood $\mathrm{T}$ lymphocytes suggests that $\mathrm{ER} \beta$ may represent a candidate predictive marker to assess responsiveness to biological therapy. However, longitudinal studies including subjects analyzed before and after the initiation of anti-TNF- $\alpha$ therapy are needed to provide conclusive evidence for a strict association between anti-TNF- $\alpha$ response and ER $\beta$ rescue.

\section{ER $\beta$ dysregulation in peripheral blood reflects that observed in intestinal mucosa}

It has been previously shown that the accumulation of ER $\beta$ transcripts is decreased in intestinal mucosa samples from IBD patients as compared to controls [12]. To assess the expression of ER $\beta$ protein in intestinal mucosa of IBD patients and to evaluate whether this expression reflects that observed in the blood, ER $\beta$ was also analyzed in whole colonic mucosa from 19 out of 48
$\mathrm{CD} / \mathrm{UC}$ patients and $10 \mathrm{age} / \mathrm{sex}$ matched HC. As shown in Figure 2A, ER $\beta$ was highly expressed in normal colonic mucosa, where a positive staining could be observed in both epithelial cells and lamina propria lymphocytes. Interestingly, a consistent reduction of ER $\beta$ expression was found in intestinal mucosa from $\mathrm{CD} / \mathrm{UC}$ subjects with active disease (Figure $2 \mathrm{~B}$ and $2 \mathrm{C}$ ) but not from those in remission (Figure $2 \mathrm{E}$ and $2 \mathrm{~F}$ ). In particular, a reduction of both epithelial cell- and lymphocyte-associated ER $\beta$ levels could be appreciated in inflamed mucosa (Figure $2 \mathrm{~B}$ and $2 \mathrm{C}$ ). Consistent with previous reports [26, 31, 32], neoplastic mucosa explanted from patients with colon adenocarcinoma $(n=5)$ displayed very low levels of ER $\beta$ expression (Figure 2D).

These results provide the first evidence that, in human colon, ER $\beta$ is markedly reduced in both CD and UC patients and the extent of its expression reflects disease activity. Of note, ER $\beta$ down-regulation in the colon tissue parallels that observed in blood $\mathrm{T}$ lymphocytes, further strengthening the role of $\mathrm{T}$ cell-associated $\mathrm{ER} \beta$ as a systemic marker of intestinal disease activity. Moreover, the finding that colonic ER $\beta$ expression inversely
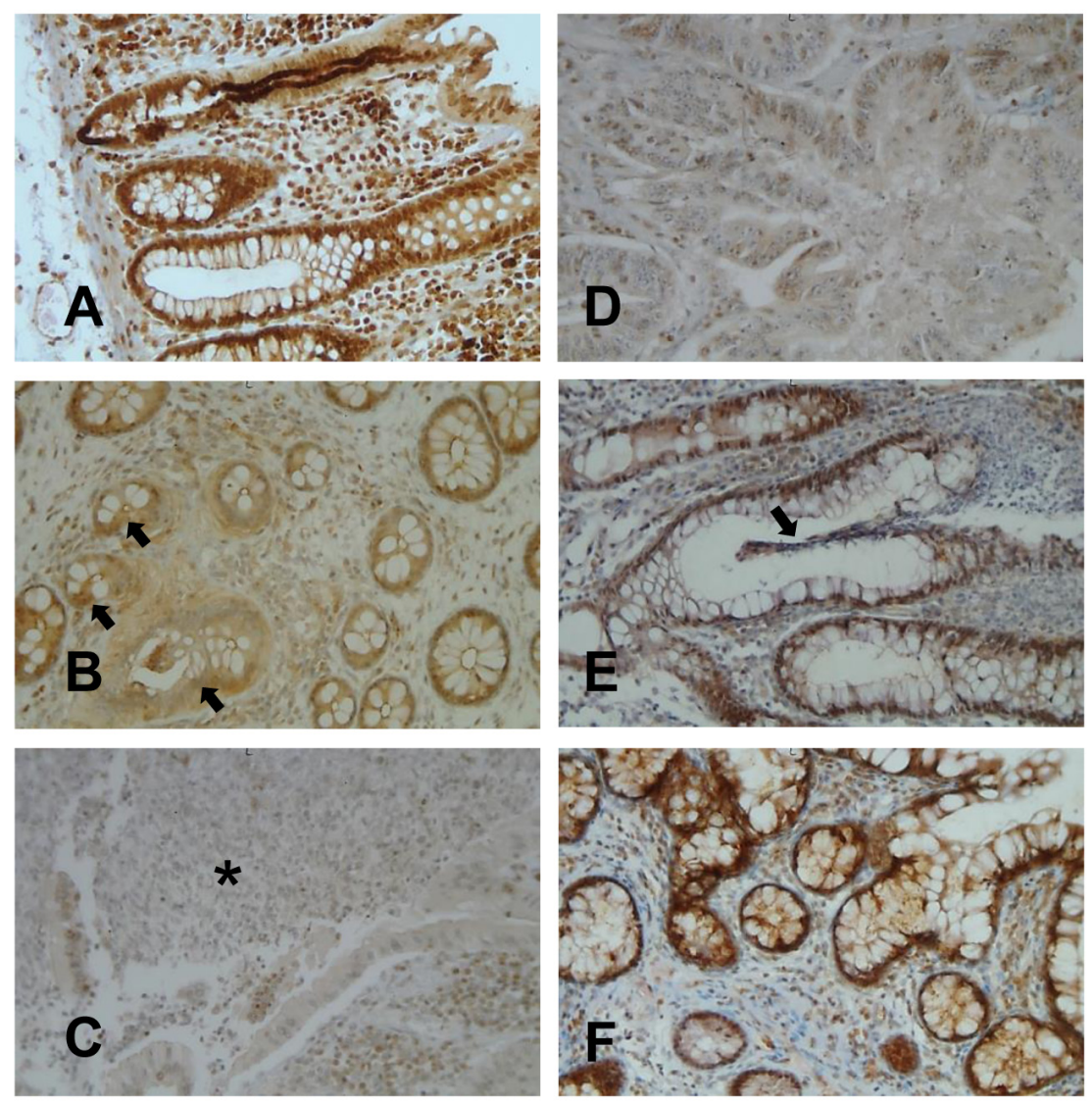

Figure 2: ERß expression in colonic mucosa from CD/UC patients. Light microscopic micrographs of typical ER $\beta$ expression (brown staining) in normal colonic mucosa A., colonic mucosa from UC B. or CD C. patients in the active phase of disease, colonic mucosa from UC E. or CD F. patients in remission, and colon adenocarcinoma D. Arrays indicate the disrupted or regenerating epithelium typical of UC mucosa in the active phase of disease B. and in remission E., respectively. The asterisk indicates the typical fistula distinguishing CD mucosa C.. One representative image of each group (UC, $n=10 ; \mathrm{CD}, n=9 ; \mathrm{HC}, n=10$; colon adenocarcinoma patients, $n=5)$ is shown (original magnifications x20). 
correlates with cancer development/progression $[26,31$, $32]$, together with our results, point to $\operatorname{ER} \beta$ as a major regulator of intestinal epithelium integrity also in the human system and suggest a role for this receptor in maintaining homeostasis. Of note, IBD represent a risk factor for CRC development [24, 25], and inflammationassociated early ER $\beta$ down-regulation might be one of the factors linking chronic intestinal diseases to neoplastic transformation.
A

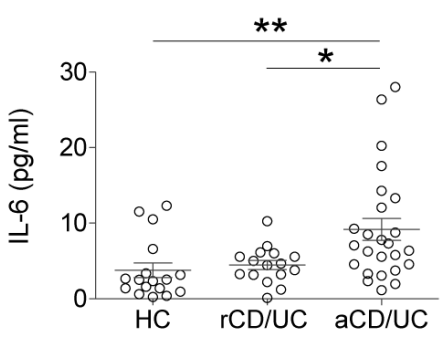

C

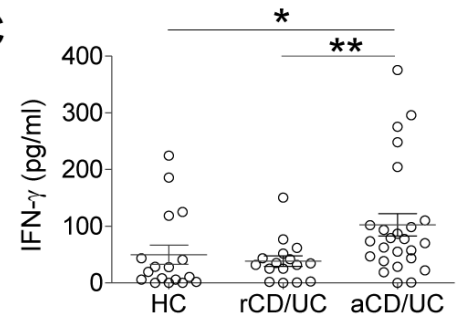

$\mathrm{E}$

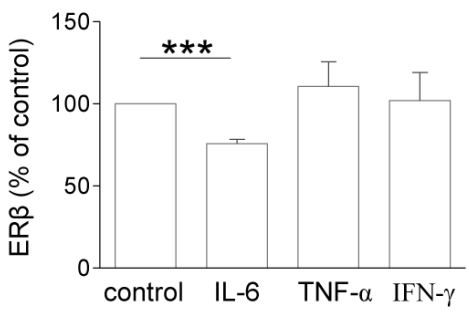

$\mathrm{F}$

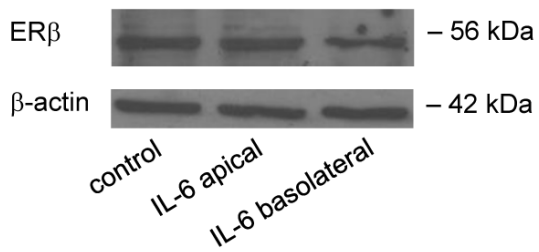

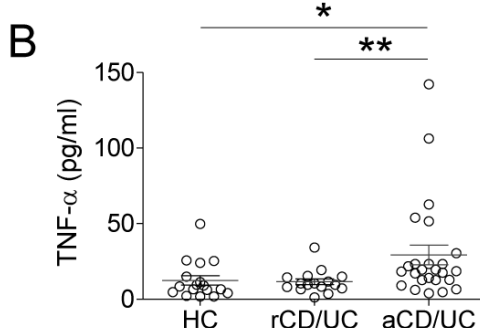

D

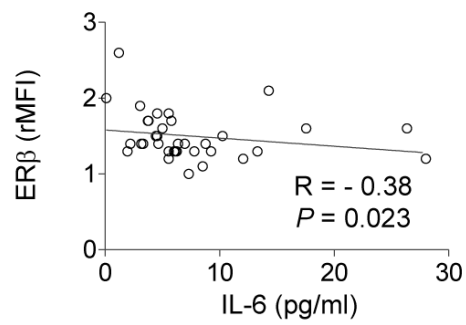

G

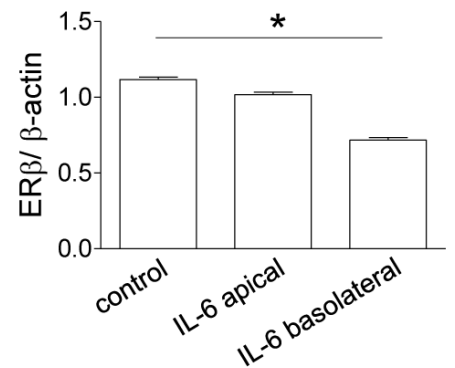

Figure 3: Plasma cytokine profile of CD/UC patients and effect of IL-6 on ERB expression in peripheral blood T lymphocytes and intestinal epithelial cells. A.-C. Cytokine plasma levels from $41 \mathrm{CD} / \mathrm{UC}$ patients $(n=25$ with active disease, $n=16$ in remission) and 17 HC. Mean \pm SEM is shown for each group. D. Correlation between plasma levels of IL-6 and ER $\beta$ expression (shown as ER $\beta$ /isotype control mean fluorescence intensity ratio, rMFI) in T lymphocytes from CD/UC patients determined by the Spearman's rank correlation test. R, Spearman's rho. E. Intracellular ER $\beta$ expression evaluated by flow cytometry in T lymphocytes from HC exposed for $72 \mathrm{~h}$ to the indicated cytokines. Data are expressed as percentage relative to untreated cells (mean \pm SEM of 5 independent experiments is shown). F., G. Western blot analysis of ER $\beta$ expression in differentiated Caco-2 cells stimulated with IL-6 at either apical or basolateral side. Data from one representative experiment out of three are shown $\mathbf{F}$. Densitometry analysis of protein levels relative to $\beta$-actin is also shown G. Values are expressed as mean \pm SEM. Statistical differences were calculated by the Mann-Whitney U test. ${ }^{*} p<0.05 ; * * p<$ $0.01 ; * * * p<0.001 . \mathrm{rCD} / \mathrm{UC}, \mathrm{CD} / \mathrm{UC}$ patients in endoscopic remission; $\mathrm{aCD} / \mathrm{UC}, \mathrm{CD} / \mathrm{UC}$ patients with endoscopic activity. 


\section{IL-6 plasma levels inversely correlate with ERß expression and exogenous exposure of both lymphocytes and intestinal epithelial cells to recombinant IL-6 results in ERß downregulation}

The unbalanced expression of ER $\alpha$ and ER $\beta$, exhibiting pro- versus anti-inflammatory features, respectively, suggests that a switch toward ER-mediated inflammatory responses occurs in $\mathrm{CD} / \mathrm{UC}$ patients. Whether the alterations of ER and ER-induced responses contribute to establish or are a consequence of the chronic inflammatory process observed in these subjects is currently unknown. The finding that a similar ER regulation occurred in both $\mathrm{CD}$ and $\mathrm{UC}$, which exhibit different localization, endoscopic findings and histological features, would support the latter hypothesis.

The analysis of soluble immune mediators in plasma samples from $\mathrm{CD} / \mathrm{UC}$ patients revealed significantly higher levels of the pro-inflammatory cytokines IL-6, TNF- $\alpha$ and IFN- $\gamma$ in subjects with active disease as compared to those in remission (Figure 3A-3C). Interestingly, a significant inverse correlation was found between ER $\beta$ expression and plasma levels of IL-6 (Figure 3D) but not those of TNF- $\alpha$ and IFN $-\gamma(\mathrm{R}=-0.10, p=0.58$, and $\mathrm{R}=-0.07, p$ $=0.69$, respectively, data not shown). No correlation was found between ER $\alpha$ expression and plasma cytokine levels (data not shown).

Based on these results, the effect of exogenous administration of IL-6 on ER $\beta$ expression was investigated. As shown in Figure 3E, exposure of control blood T lymphocytes to IL-6 significantly reduced ER $\beta$ expression, whereas TNF- $\alpha$ and IFN- $\gamma$ did not exert any effect. Conversely, ER $\alpha$ levels were not significantly modulated by these cytokines (data not shown). To assess whether intestinal ER $\beta$ expression could be regulated as a result of inflammatory cytokine stimulation, Caco-2 cellderived normal epithelium was exposed to IL- 6 at either apical or basolateral sides. Consistent with the results obtained in T cells, IL-6 was found to downregulate ER $\beta$ expression in intestinal epithelial cells. Notably, this effect was observed when IL-6 was added to the basolateral but not to the apical side (Figure 3F and 3G), thus resembling the cross-talk between intestinal epithelium and lamina propria immune cells occurring in vivo [33].

Although the mechanism(s) underlying ER $\beta$ regulation remain to be further elucidated, our results show that the pro-inflammatory cytokine IL-6, whose levels we found increased in serum from IBD patients with active disease, contributes to regulate ER expression in $\mathrm{T}$ lymphocytes and in in vitro-generated intestinal epithelium. IL-6 has been recently reported to negatively regulate ER $\beta$ expression in ovarian cancer cell lines [34]. To the best of our knowledge, this is the first demonstration that this cytokine can regulate ER $\beta$ expression in intestinal epithelium and blood $\mathrm{T}$ cells, suggesting that the inflammatory microenvironment of IBD patients plays a role in controlling the ER $\alpha / E R \beta$ balance. In keeping with this hypothesis, the potential of IL-6 targeting as a therapeutic strategy in IBD is under investigation [35].

A deeper characterization of factors and mechanisms controlling ER expression and function may increase our knowledge on the pathogenesis of IBD and open new perspectives for the comprehension and management of the disease. Further analysis using ER $\alpha$ and ER $\beta$ selective agonists will allow to more deeply investigate the ERmediated responses elicited in chronic inflammatory conditions, and to study the potential role of ER as therapeutic target. Reliable biomarkers of disease activity as well as of response to therapy are not yet available in IBD. Thus, identifying new factors/mechanisms that are dysregulated in IBD patients may open new perspectives for the comprehension of disease pathogenesis and clinical management. Overall, our results indicate that a better understanding of the role of ERs may advance our knowledge of these complex diseases, and lead to novel therapeutic options.

\section{MATERIALS AND METHODS}

\section{Ethics statement}

Investigation has been conducted in accordance with the ethical standards and according to the Declaration of Helsinki and according to national and international guidelines and has been approved by the authors' institutional review board. All the subjects included were provided with complete information about the study and asked to sign an informed consent.

\section{Patients and biological samples}

Biological samples were obtained from patients with documented $\mathrm{CD}(n=26)$ or UC $(n=22)$ attending to the Digestive Endoscopy Unit (Catholic University, Rome, Italy), the Gastroenterology and Digestive Endoscopy (Nuovo Regina Margherita Hospital, Rome, Italy), and the IBD Unit (Complesso Integrato Columbus, Catholic University, Rome, Italy). Endoscopic biopsies from 5 patients with colon adenocarcinoma were obtained from the Histopathology Complex Unit (Santo Spirito Hospital, Rome, Italy). Twenty-nine healthy controls (HC) matched for age and sex made up a control group. The exclusion criteria were: clinical evidence of active infection, recent (within 14 days) use of antibiotics, pregnancy, hormonebased therapy, and treatment with corticosteroids (methylprednisolone or equivalents) at doses $>20 \mathrm{mg}$ /day. Patients undergoing anti-TNF- $\alpha$ therapy were analyzed after at least 6 months from the initiation of therapy and 
blood ER expression was determined the week before the next anti-TNF- $\alpha$ administration. Endoscopic results were assessed according to the Crohn's Disease Endoscopic Index of Severity (CDEIS, remission when score $<3$ ) [36] for CD, the Rutgeerts score (remission when score = i0) [37] for post-operative CD, and the Mayo endoscopic sub-score (remission when score $=0$ ) [38] for UC. Blood samples were drawn at the time of obtaining peripheral vein access for the endoscopic procedure. Plasma were frozen soon after collection and stored at $-80^{\circ} \mathrm{C}$ until used. Endoscopic biopsies were taken from colon/ileum tissue of IBD patients, whereas surgical specimens of colonic mucosa, from both neoplastic and adjacent ( $>5 \mathrm{~cm}$ distal) macroscopically non-neoplastic regions, were obtained from subjects with colon adenocarcinoma. Intestinal mucosa was fixed in $10 \%$ formalin and stored for further processing.

\section{Isolation of peripheral blood mononuclear cells and cell culture conditions}

Peripheral blood mononuclear cells were isolated by Ficoll-Hypaque density-gradient centrifugation. Untouched T cells were subsequently separated using the Pan T Cell isolation Kit II (Miltenyi Biotec, BergischGladbach, Germany). The purity of recovered cells, assessed by flow cytometer, was $\geq 97 \%$. For ER analysis, cells were processed soon after isolation. For cytokine stimulation, $\mathrm{T}$ cells isolated from $\mathrm{HC}$ were seeded in RPMI-1640 medium without phenol red (GIBCO BRL, Grand Island, NY, USA) supplemented with 10\% charcoalstripped fetal bovine serum (FBS, Euroclone, Pero, Milan, Italy), 2mM glutamine (Sigma, St. Louis, MO, USA) 50 $\mu \mathrm{g} / \mathrm{ml}$ gentamycin (Sigma), and exposed for 72 hours to IL-6 or TNF- $\alpha$ (Peprotech, Rocky Hill, NJ, USA; 50 ng/ $\mathrm{ml}$ ) or IFN- $\gamma$ (Peprotech, $500 \mathrm{IU} / \mathrm{ml}$ ) before ER analysis. The 72 hour time point as well as the concentrations used were chosen on the basis of preliminary time course and dose-response experiments showing that these conditions were those at which the highest changes of ER expression could be detected.

\section{Flow cytometry}

Intracellular phenotyping of $\mathrm{T}$ cells was performed by flow cytometry as previously described [21]. FITCconjugated rabbit anti-human $\mathrm{ER} \alpha$ antibody $(\mathrm{Ab}$, clone MC-20) or mouse anti-human ER $\beta$ (clone 1531) Ab, both from Santa Cruz Biotechnology (Santa Cruz, CA, USA), were used. Equal amounts of appropriate isotype controls (Santa Cruz Biotechnology) were used. Anti-human $\mathrm{ER} \beta \mathrm{Ab}$ was visualized by fluorescein isothiocyanateconjugated $\mathrm{F}(\mathrm{ab}$ ')2 fragment secondary Ab (Abcam, Cambridge, UK). Allophycocyanin conjugated anti-CD3, phycoerythrin conjugated anti-CD4, peridinin chlorophyll protein-conjugated anti-CD8 monoclonal Abs (all from BD Biosciences, San Jose, CA, USA) were also used to identify $\mathrm{ER} \alpha$ and $\mathrm{ER} \beta$ expression in lymphocyte subsets. Acquisition was performed on a FACSCalibur cytometer (BD Biosciences) and 50,000 events per sample were run. Data were analyzed using the Cell Quest Pro (BD Biosciences) software.

\section{Quantification of plasma cytokine/chemokine levels}

The analysis of cytokine content in plasma samples of randomly selected $\mathrm{HC}$ and IBD patients was performed by using the Bio-Plex Pro Human Cytokine 27-plex Assay (Bio-Rad Laboratories, Hercules, CA, USA) according to the manufacturer's instructions. This assay was able to concomitantly detect the following cytokines, chemokines and growth factors: IL-1 $\beta$, IL-1ra, IL-2, IL-4, IL-5, IL6, IL-7, IL-8, IL-9, IL-10, IL-12 (p70), IL-13, IL-15, IL17 , Basic FGF, Eotaxin, G-CSF, GM-CSF, IFN- $\gamma$, IP-10, MCP-1 (MCAF), MIP-1 $\alpha$, MIP-1 $\beta$, PDGF-BB, RANTES, TNF- $\alpha$, VEGF. The assay was performed at the Facility for Complex Protein Mixture (CPM) Analysis (Istituto Superiore di Sanità, Rome, Italy).

\section{Immunohistochemistry analysis}

Intestinal mucosa sections were mounted on to superfrost microscope slides and immunostaining of ER $\beta$ was performed. Mouse anti-human ER $\beta$ Ab (clone 14C8, Abcam) was applied at a dilution of 1:200 for 60 minutes at $37^{\circ} \mathrm{C}$. Antigen retrieval was performed with Cell Conditioning (CC1, Ventana Medical Systems, Illkirch, France) for 60 minutes at $98^{\circ} \mathrm{C}$. The $\mathrm{Ab}$ reactions were revealed using the ultraView Universal DAB (Ventana Medical Systems). ER $\beta$ staining of neoplastic mucosa from subjects with colon adenocarcinoma was also performed, whereas adjacent normal mucosa $(>5 \mathrm{~cm}$ distal from the neoplastic lesion) was used as a positive control. Sections incubated after the omission of the primary Ab were used as negative controls. The sections were counterstained with haematoxylin, dehydrated and mounted on glass coverslips. All samples were observed and photographed with a Zeiss Axiovert microscope.

\section{Caco-2 cell based model of intestinal epithelium and western blot analysis of ER $\beta$ expression}

Polarized human intestinal epithelium was obtained by culturing Caco-2 cells (ATCC \#HTB-37) on polycarbonate-coated trans-well chambers $\left(8 \times 10^{4}\right.$ cell/ $\mathrm{cm}^{2}$ ) in high glucose Dulbecco's Modified Eagle Medium (DMEM) plus 10\% FBS and nonessential amino acids for 21 days as previously described [39]. Trans epithelial 
electrical resistance was monitored throughout the differentiation period. Differentiated cell cultures were then stimulated for 24 hours with recombinant IL-6 (50 $\mathrm{ng} / \mathrm{ml}$ ) at either apical or basolateral sides, then harvested and lysed in RIPA buffer. Intracellular ER $\beta$ expression analysis was performed by western blot as previously described [21], using a mouse anti-human ER $\beta$ Ab (clone 1531, Santa Cruz Biotechnology). To ensure the presence of equal amounts of protein, the membranes were reprobed with a rabbit anti-human $\beta$-actin Ab (Sigma).

\section{Statistics}

The Mann-Whitney U test was used for comparisons between different groups. Correlations were evaluated using Spearman's rank correlation test. Linear regression analysis was performed to display a best fit line to the data. Statistical analyses were performed using GraphPad Prism 5 software. All tests were 2 -sided and a $p$ value $<$ 0.05 was considered statistically significant.

\section{ACKNOWLEDGEMENTS}

We thank C. Angelini and S. Rossi for helpful technical support, G. Costamagna and A. Armuzzi for having supported this study.

\section{CONFLICTS OF INTEREST}

None of the authors have any conflicts to disclose.

\section{GRANT SUPPORT}

This work was supported by the ISS Italy-NIH USA collaborative project 11US/13 (Italian Ministry of Health) to $\mathrm{SG}$.

\section{REFERENCES}

1. Baumgart DC, Carding SR. Inflammatory bowel disease: cause and immunobiology. Lancet. 2007; 369: 1627-1640.

2. Wallace KL, Zheng LB, Kanazawa Y, Shih DQ. Immunopathology of inflammatory bowel disease. World J Gastroenterol. 2014; 20: 6-21.

3. Ben-Horin S, Chowers Y. Tailoring anti-TNF therapy in IBD: drug levels and disease activity. Nat Rev Gastroenterol Hepatol. 2014; 11: 243-255.

4. Kane SV, Reddy D. Hormonal replacement therapy after menopause is protective of disease activity in women with inflammatory bowel disease. Am J Gastroenterol. 2008; 103: 1193-1196.

5. Riis L, Vind I, Politi P, Wolters F, Vermeire S, Tsianos E, Freitas J, Mouzas I, Ruiz Ochoa V, O'Morain C, Odes $\mathrm{S}$, Binder V, Moum B, et al. Does pregnancy change the disease course? A study in a European cohort of patients with inflammatory bowel disease. Am J Gastroenterol. 2006; 101: 1539-1545.

6. Khalili H, Higuchi LM, Ananthakrishnan AN, Richter JM, Feskanich D, Fuchs CS, Chan AT. Oral contraceptives, reproductive factors and risk of inflammatory bowel disease. Gut. 2013; 62: 1153-1159.

7. Babickova J, Tothova L, Lengyelova E, Bartonova A, Hodosy J, Gardlik R, Celec P. Sex Differences in Experimentally Induced Colitis in Mice: a Role for Estrogens. Inflammation. 2015; 38: 1996-2006.

8. Brant SR, Nguyen GC. Is there a gender difference in the prevalence of Crohn's disease or ulcerative colitis? Inflamm Bowel Dis. 2008; 14 Suppl 2: S2-3.

9. Chadwick CC, Chippari S, Matelan E, Borges-Marcucci L, Eckert AM, Keith JC, Jr., Albert LM, Leathurby Y, Harris HA, Bhat RA, Ashwell M, Trybulski E, Winneker RC, et al. Identification of pathway-selective estrogen receptor ligands that inhibit NF-kappaB transcriptional activity. Proc Natl Acad Sci U S A. 2005; 102: 2543-2548.

10. Harnish DC, Albert LM, Leathurby Y, Eckert AM, Ciarletta A, Kasaian M, Keith JC, Jr. Beneficial effects of estrogen treatment in the HLA-B27 transgenic rat model of inflammatory bowel disease. Am J Physiol Gastrointest Liver Physiol. 2004; 286: G118-125.

11. Harris HA. Preclinical characterization of selective estrogen receptor beta agonists: new insights into their therapeutic potential. Ernst Schering Found Symp Proc. 2006: 149-161.

12. Looijer-van Langen M, Hotte N, Dieleman LA, Albert E, Mulder C, Madsen KL. Estrogen receptor-beta signaling modulates epithelial barrier function. Am J Physiol Gastrointest Liver Physiol. 2011; 300: G621-626.

13. Saleiro D, Murillo G, Benya RV, Bissonnette M, Hart J, Mehta RG. Estrogen receptor-beta protects against colitisassociated neoplasia in mice. Int J Cancer. 2012; 131: 25532561.

14. Verdu EF, Deng Y, Bercik P, Collins SM. Modulatory effects of estrogen in two murine models of experimental colitis. Am J Physiol Gastrointest Liver Physiol. 2002; 283: G27-36.

15. Straub RH. The complex role of estrogens in inflammation. Endocr Rev. 2007; 28: 521-574.

16. Ngo ST, Steyn FJ, McCombe PA. Gender differences in autoimmune disease. Front Neuroendocrinol. 2014; 35: 347-369.

17. Whitacre CC. Sex differences in autoimmune disease. Nat Immunol. 2001; 2: 777-780.

18. Ascenzi P, Bocedi A, Marino M. Structure-function relationship of estrogen receptor alpha and beta: impact on human health. Mol Aspects Med. 2006; 27: 299-402.

19. Phiel KL, Henderson RA, Adelman SJ, Elloso MM. Differential estrogen receptor gene expression in human peripheral blood mononuclear cell populations. Immunol Lett. 2005; 97: 107-113. 
20. Shim GJ, Gherman D, Kim HJ, Omoto Y, Iwase H, Bouton D, Kis LL, Andersson CT, Warner M, Gustafsson JA. Differential expression of oestrogen receptors in human secondary lymphoid tissues. J Pathol. 2006; 208: 408-414.

21. Pierdominici M, Maselli A, Colasanti T, Giammarioli AM, Delunardo F, Vacirca D, Sanchez M, Giovannetti A, Malorni W, Ortona E. Estrogen receptor profiles in human peripheral blood lymphocytes. Immunol Lett. 2010; 132: 79-85.

22. Wada-Hiraike O, Imamov O, Hiraike H, Hultenby K, Schwend T, Omoto Y, Warner M, Gustafsson JA. Role of estrogen receptor beta in colonic epithelium. Proc Natl Acad Sci U S A. 2006; 103: 2959-2964.

23. Wada-Hiraike O, Warner M, Gustafsson JA. New developments in oestrogen signalling in colonic epithelium. Biochem Soc Trans. 2006; 34: 1114-1116.

24. Ullman TA, Itzkowitz SH. Intestinal inflammation and cancer. Gastroenterology. 2011; 140: 1807-1816.

25. Dyson JK, Rutter MD. Colorectal cancer in inflammatory bowel disease: what is the real magnitude of the risk? World J Gastroenterol. 2012; 18: 3839-3848.

26. Campbell-Thompson M, Lynch IJ, Bhardwaj B. Expression of estrogen receptor (ER) subtypes and ERbeta isoforms in colon cancer. Cancer Res. 2001; 61: 632-640.

27. Barzi A, Lenz AM, Labonte MJ, Lenz HJ. Molecular pathways: Estrogen pathway in colorectal cancer. Clin Cancer Res. 2013; 19: 5842-5848.

28. Principi M, Barone M, Pricci M, De Tullio N, Losurdo G, Ierardi E, Di Leo A. Ulcerative colitis: from inflammation to cancer. Do estrogen receptors have a role? World J Gastroenterol. 2014; 20: 11496-11504.

29. Park JM, Han NY, Han YM, Chung MK, Lee HK, Ko KH, Kim EH, Hahm KB. Predictive proteomic biomarkers for inflammatory bowel disease-associated cancer: where are we now in the era of the next generation proteomics? World J Gastroenterol. 2014; 20: 13466-12476.

30. Falvey JD, Hoskin T, Meijer B, Ashcroft A, Walmsley R, Day AS, Gearry RB. Disease activity assessment in IBD: clinical indices and biomarkers fail to predict endoscopic remission. Inflamm Bowel Dis. 2015; 21: 824-831.

31. Konstantinopoulos PA, Kominea A, Vandoros G, Sykiotis GP, Andricopoulos P, Varakis I, Sotiropoulou-Bonikou G, Papavassiliou AG. Oestrogen receptor beta (ERbeta) is abundantly expressed in normal colonic mucosa, but declines in colon adenocarcinoma paralleling the tumour's dedifferentiation. Eur J Cancer. 2003; 39: 1251-1258.

32. Rudolph A, Toth C, Hoffmeister M, Roth W, Herpel E, Jansen L, Marx A, Brenner H, Chang-Claude J. Expression of oestrogen receptor beta and prognosis of colorectal cancer. Br J Cancer. 2012; 107: 831-839.

33. Wittkopf N, Neurath MF, Becker C. Immune-epithelial crosstalk at the intestinal surface. J Gastroenterol. 2014; 49: 375-387.

34. Wang Y, Qu Y, Zhang XL, Xing J, Niu XL, Chen X, Li
ZM. Autocrine production of interleukin- 6 confers ovarian cancer cells resistance to tamoxifen via ER isoforms and SRC-1. Mol Cell Endocrinol. 2014; 382: 791-803.

35. Allocca M, Jovani M, Fiorino G, Schreiber S, Danese S. Anti-IL-6 treatment for inflammatory bowel diseases: next cytokine, next target. Curr Drug Targets. 2013; 14: 15081521.

36. Mary JY, Modigliani R. Development and validation of an endoscopic index of the severity for Crohn's disease: a prospective multicentre study. Groupe d'Etudes Therapeutiques des Affections Inflammatoires du Tube Digestif (GETAID). Gut. 1989; 30: 983-989.

37. Rutgeerts P, Geboes K, Vantrappen G, Beyls J, Kerremans R, Hiele M. Predictability of the postoperative course of Crohn's disease. Gastroenterology. 1990; 99: 956-963.

38. Schroeder KW, Tremaine WJ, Ilstrup DM. Coated oral 5-aminosalicylic acid therapy for mildly to moderately active ulcerative colitis. A randomized study. N Engl J Med. 1987; 317: 1625-1629.

39. Markowska M, Oberle R, Juzwin S, Hsu CP, Gryszkiewicz $\mathrm{M}$, Streeter AJ. Optimizing Caco-2 cell monolayers to increase throughput in drug intestinal absorption analysis. $\mathrm{J}$ Pharmacol Toxicol Methods. 2001; 46: 51-55. 